\title{
Single Nucleotide Polymorphism-Based Analysis of Cell-Free Fetal DNA in 3000 Cases from Germany and Austria
}

Authors

Affiliations
B. Eiben ${ }^{1}$, M. Krapp ${ }^{2}$, H. Borth ${ }^{3}$, N. Kutur ${ }^{4}$, P. Kreiselmaier ${ }^{5}$, R. Glaubitz ${ }^{6}$, J. Deutinger ${ }^{7}$, E. Merz

Affiliation addresses are listed at the end of the article
Key words

- laboratory tests

- pregnancy

- chromosomal aberration

- down syndrome

screening

\section{Abstract \\ $\nabla$}

Background \& Patient: Data from 3008 patients, who underwent single-nucleotide-polymorphism (SNP)-based noninvasive prenatal testing (NIPT) are presented.

Method: The PanoramaTM test (Natera, San Carlos, CA) was used to analyze cell-free fetal DNA from maternal blood for trisomies 21,18 , and 13 , triploidy and sex-chromosome aneuploidies.

Result: In $2942(97.8 \%)$ cases, a result was obtained. The average fetal fraction was $10.2 \%$. A high-risk result for fetal aneuploidy was made for $65(2.2 \%)$ cases. In $59(90.8 \%)$ of these cases,

Introduction

received $\quad 15.01 .2015$

accepted $\quad 29.05 .2015$

Bibliography

DOI http://dx.doi.org/ 10.1055/s-0035-1555765

Published online:

June 26, 2015

Ultrasound International Open

2015; 1: E8-E11

(c) Georg Thieme Verlag KG

Stuttgart · New York

ISSN 2199-7152

Correspondence

Dr. Bernd Eiben

Labor Eiben Glaubitz

Institut für Klinische Genetik

Nordrhein

Willy Brandt Platz 4

45127 Essen

Germany

Tel.: + 49/201/747 760

Fax: $+49 / 201 / 7477690$

eiben@eurogen.de

\section{$\nabla$}

In the last 2 years, the introduction of commercial noninvasive prenatal tests (NIPT) has led to a dramatic change in prenatal testing strategies worldwide. These tests are based on massively of single-nucleotide polymorphisms (SNP) [7-9]. By using a proprietary algorithm, a biostatistical estimation of risk [6], high sensitivity and specificity for the detection of aneuploidies of the chromosomes $21,18,13, \mathrm{X}$ and $\mathrm{Y}$, and triploidies can be achieved with NIPT technology [7-9]. Here we report on our experience with more than 3000 commercial NIPTs in Germany and Austria that were performed using the SNP approach.

\section{Materials \& Methods}

This retrospective study included NIPT data of blood samples collected between June 2013 and August 2014. Pretest genetic counseling was performed according to the German and Austrian legal regulations (Gene Diagnostic Act). parallel shotgun sequencing [1-6] or on analyses invasive testing confirmed the aneuploidy. There were 6 false-positive cases. In the false-positive group, the fetal fraction was significantly lower. The overall positive predictive value was $90.8 \%$. No false-negative cases were reported but many patients in this study have not delivered yet. Therefore, exact data cannot be given for potential false-negative cases.

Conclusion: SNP-based NIPT is a reliable screening method for evaluating the risk of aneuploidies of chromosomes 21, 18 and 13. By using NIPT, the number of invasive procedures may be reduced significantly compared to maternal age and first-trimester screening. 
reported by Natera, with risk scores $\geq 1: 100$ considered as high risk and those $<1: 100$ as low risk. The referring gynecologist or human geneticist received a medical report from the Amedes laboratory with an individual recommendation for the patient. According to German regulations, only this gynecologist or human geneticist was permitted to advise the pregnant woman on the result and on her options for further testing.

Follow-up information was acquired by phone. In cases of increased risk for aneuploidies in NIPT, the exact genetic diagnosis of invasive karyotyping was ascertained. Descriptive data analysis was performed. Where applicable, the t-test was used for statistical analysis. $\mathrm{p}<0.05$ was accepted as significant.

\section{Results}

$\nabla$

For most of the 3008 pregnant women who elected for SNPbased NIPT, tests were performed in the first trimester of pregnancy ( $\bullet$ Table 1 ). Only $3.1 \%$ of tests were performed beyond 20 weeks of gestation.

The indications for NIPT, mean maternal age and the number of high-risk NIPT findings are listed in $\odot$ Table 2 . The mean maternal age was 37 years over all 3008 cases. In the screening group, for nearly all cases complete first-trimester screening with nuchal translucency, PAPP-A and free B-hCG was performed.

Final reporting was feasible for 2942 (97.8\%) of all 3008 cases. These 2942 cases included 56 cases, in which a final result could be obtained after redraw of a blood sample, and 36 cases, in which a drop out for the risk score of one chromosome occurred, while the remaining cases were fully analyzed. Panorama test was not informative in 66 cases $(2.2 \%)$, because of a fetal frac-

Table 1 Number of NIPT samples and mean fetal fraction stratified by gestational age.

\begin{tabular}{|lcc|} 
Gestational week & $\mathbf{n}(\%)$ & Fetal fraction (\%) \\
$\mathbf{9 + 0 - 1 0 + 6}$ & $505(16.8 \%)$ & 9.3 \\
\hline $\mathbf{1 1 + 0 - 1 3 + 6}$ & $1471(48.9 \%)$ & 10.2 \\
\hline $\mathbf{1 4 + 0 - 1 9 + 6}$ & $939(31.2 \%)$ & 10.4 \\
\hline $\mathbf{2 0 + 0}$ & $93(3.1 \%)$ & 12.8 \\
Total & $\mathbf{3 0 0 8}$ & $\mathbf{1 0 . 2}$
\end{tabular}

Table 2 Indications for NIPT, mean maternal age in these groups and number of high-risk NIPT findings.

\begin{tabular}{lccc|} 
Indication & $\mathbf{n ( \% )}$ & Mat. age & High-risk aneuploidy \\
Screening & $669(22.3)$ & 36 & $35(5.2 \%)$ \\
\hline Adv. maternal age & $1815(60.3)$ & 39 & $25(1.4 \%)$ \\
Other & $524(17.4)$ & 31 & $5(1 \%)$ \\
Total & 3008 & 37 & $65(2.2)$
\end{tabular}

tion $<4 \%$ or an uninformative DNA pattern or poor DNA quality or vanishing twins. The mean turnaround time for blood sampling, transportation, analysis and reporting was 11 days.

In $97.8 \%$ of these cases, the result was considered low-risk ( 0 Table 3). One case with triple X and 2 cases with a XYY karyotype were revealed by NIPT, but were classified also into the low-risk group of this study. High-risk results were reported for trisomy $21,18,13$, sex chromosome aneuploidies, and triploidies ( 0 Table 3). The fetal fraction was slightly higher in trisomy 21 cases compared to the low-risk cases, but it was significantly lower in trisomy 13 cases.

For all high-risk cases, complete follow-up data were collected, except for one case each monosomy $\mathrm{X}$. In most high-risk cases, the risk score was $>99 \%$ and this could be confirmed by invasive cytogenetic analysis. We found one false-positive case for trisomy 18 with a reported risk score was $70.8 \%$ and a fetal fraction of $5.4 \%$ and one false-positive monosomy $\mathrm{X}$ case. Another falsepositive case was revealed in a case of suspected trisomy 21 with a reported fetal fraction of $4.0 \%$ and a risk score of $94 \%$. In the trisomy 13 high-risk group, there were 3 false-positive cases. In 36 cases ( $\bullet$ Table 4 ) a risk score for one of the analyzed chromosomes could not be determined (not called). The most common not analyzable chromosome was the $\mathrm{X}$ chromosome. The average fetal fraction in cases in which the $\mathrm{X}$ chromosome was not called was slightly lower than in the full cohort. For cases in which an autosome was not called, the average fetal fraction was significantly lower than the full cohort. All 36 cases were considered to be in the low-risk group because no further aberrance was observed within the pregnancy or after birth.

Details of the trisomy 13 high-risk cases are shown in $\bullet$ Table 5 . In 3 of 8 cases with a high-risk score for trisomy 13, the finding could not be confirmed by amniocentesis. The mean fetal fraction in the high-risk group for trisomy 13 was significantly lower ( $\mathrm{t}$-test $\mathrm{p}=0.003$ ) compared with the low-risk group.

\section{Discussion \\ $\nabla$}

NIPT has rapidly changed the traditional approach to prenatal screening and diagnosis and has led to changes in the guidelines of medical societies. According to the ISUOG guidelines [14], all women should be offered first-trimester ultrasound and pretest counseling about NIPT. The German Society of Human Genetics published a comprehensive opinion in late 2013 recommending that NIPT should be available for all pregnant women [12]. Other societies, like the Fetal Medicine Foundation Germany supported the use of NIPT under certain indications [13].

Because NIPT is not covered by German or Austrian public health insurance, the use of NIPT must be paid for out-of-pocket by patients. Consequently, a study of commercial NIPT data is an

\begin{tabular}{|c|c|c|c|c|c|}
\hline Result & $\mathbf{n}$ & n FP & PPV & Fetal fraction (\%) & Mat. age \\
\hline Low risk & 2841 & & & 10.3 & 37 \\
\hline Low risk but in 1 chromosome no risk score & 36 & & \multicolumn{3}{|c|}{ 4.9-7.7 ( $($ Table 4) } \\
\hline High risk + 21 & 39 & 1 & $97.4 \%$ & 11.8 & 39 \\
\hline High risk + 18 & 9 & 1 & $88.9 \%$ & 8 & 39 \\
\hline High risk + 13 & 8 & 3 & $62.5 \%$ & 6.1 & 40 \\
\hline High risk monosomy $X$ & 5 & 1 & $80 \%$ & 9.9 & 35 \\
\hline High risk triploidy & 4 & & $100 \%$ & & \\
\hline Total & 2942 & & & & \\
\hline
\end{tabular}

Table 3 NIPT results, number of cases, number of false-positives (FP), positive predictive value (PPV), fetal fraction and mean maternal age. 
expression of the economic situation of the participants, and may explain, at least in part, the high proportion of advanced maternal age indication in this study.

Nicolaides et al. [20] recently determined that NIPT is the best screening strategy for detecting trisomies 21,18 and 13 and is far superior to the performance of all currently available methods that rely on maternal age, ultrasound examination of the fetus, and maternal serum biochemistry.

However, hand first-trimester screening could be implemented as a pre-screening tool in prenatal care to reduce the economic cost of NIPT. In the indication group "abnormal first-trimester screening" of this study, $5.2 \%$ of cases were aneuploid. This is considerably higher than in other indication groups (1.4 and $1.0 \%$ ) and demonstrates the benefit of pre-screening by a contingency screening approach.

In this study 65 cases with high-risk scores for aneuploidies were reported. In 59 cases (90.8\%) amniocentesis or CVS revealed a trisomy, a monosomy $\mathrm{X}$ or a triploidy. There were 6 false-positive cases.

One of the main causes of false-positive NIPT results is confined placental mosaicism (CPM), with a different genetic status of the fetus and the placenta. The cell-free fetal DNA source for NIPT analysis is derived from placental cells [21]. Thus, analysis of aneuploidies by NIPT faces similar problems as in chorionic villi sampling (CVS), in which a discrepancy between embryoblast and trophoblast is observed in $1-2 \%$ of cases [15-18]. CPM is especially common in trisomy 18 and 13 placentas [19]. In CPM cases, an NIPT result may be analytically accurate, while being clinically considered as a false-positive result.

In this study there were 6 cases with discordant results between an abnormal NIPT and normal cytogenetic testing of the pregnancy. In nearly all true-positive (TP) cases the risk score was >99\% (except 1 TP trisomy 21 case with $48.6 \%$ risk). In nearly all false-positive results, a fetal fraction below $6 \%$ was observed and the risk score was far below $99 \%$. Fetal fractions below $8 \%$ are problematic [22]. The constellation "very low fetal fraction and risk score $<99 \%$ " may be indicative of fetal-placental discrepancies, especially in pregnancies with normal ultra-

Table 436 cases with a partial risk score (no risk score for one chromosome) and fetal fraction.

\begin{tabular}{|llrc|}
$\begin{array}{l}\text { Low risk for } \\
\text { chromosomes }\end{array}$ & $\begin{array}{l}\text { No risk score for } \\
\text { chromosome }\end{array}$ & $\mathbf{n}$ & \multicolumn{2}{l}{$\begin{array}{l}\text { Fetal fraction } \\
\text { (\%) }\end{array}$} \\
\hline $\mathbf{2 1 , \mathbf { 1 8 } , \text { gonosomes }}$ & $\mathbf{1 3}$ & 10 & 4.9 \\
\hline $\mathbf{2 1 , \mathbf { 1 3 } , \text { gonosomes }}$ & $\mathbf{1 8}$ & 7 & 5.5 \\
\hline $\mathbf{1 3} \mathbf{1 8}$ gonosomes & $\mathbf{2 1}$ & 2 & 6.0 \\
\hline $\mathbf{2 1 , \mathbf { 1 8 }} \mathbf{1 3}$ & $\mathbf{X}$ & 17 & 7.7 \\
\hline
\end{tabular}

Table 5 High-risk cases for trisomy 13 and details for fetal fraction, risk score and cytogenetic fetal outcome ( $F P=$ false positive; $+13=$ trisomy 13 confirmed).

\begin{tabular}{|cccc|} 
Case no. & Fetal fraction (\%) & Risk score (\%) & Outcome \\
\hline 320 & 4.7 & 10 & FP \\
\hline 1780 & 4.8 & 37.5 & FP \\
\hline 934 & 4.1 & 90 & FP \\
\hline 1384 & 7.6 & 99 & +13 \\
\hline 1999 & 8.7 & 99 & +13 \\
\hline 2136 & 7.7 & 99 & +13 \\
\hline 2572 & 7.0 & 99 & +13 \\
\hline 2876 & 4.3 & 99 & +13 \\
\hline
\end{tabular}

sound. Low fetal fractions may also be due to small or dysfunctional placentas in which aneuploidies are observed [23]. Data of this study found that trisomy 13 cases had significantly lower average fetal fractions, which confirms findings of Rava et al. [24]. Additionally, the positive predictive value (PPV) in trisomy 13 high-risk cases in this study was much lower (62.5\%) compared to trisomy 21 and 18 PPVs (97.4 and 88.9\% respectively). This supports the findings of Dar et al. [25], who observed similar PPV trends among autosomal trisomies (38.1\% for T13, 93.1\% for T18, and 90.9\% for T21). Their overall PPV for all 4 aneuploidies was $83 \%$ compared to $90.8 \%$ in this study.

Bianchi et al. demonstrated a 10-fold PPV improvement for trisomy 21 using NIPT compared to other screening methods [26]. Because many patients in this study have not yet delivered, no exact data can be given for potential false-negative cases and the negative predictive value in the low-risk group. As of now, we are not aware of any false-negative cases or other discrepancies. Despite the obvious progress through these new techniques, NIPT is not considered a diagnostic test and cannot be used as a standalone test without ultrasound examination [27] or invasive confirmation. Because nuchal translucency provides more information than just aneuploidy status, detailed ultrasound is strongly recommended for all patients.

\section{Conclusion}

$\nabla$

SNP-based NIPT is a reliable screening method for trisomies $21,18,13$ and triploidy. Use of NIPT reduces the numbers of invasive procedures performed, as compared to the use of maternal age alone as a risk factor. Although NIPT may be performed from gestation week 9 onwards, recent publications discuss the combination with first-trimester screening to reduce the amount of NIPT tests without decreasing the detection rate for chromosomal aneuploidies [1]. Any high-risk score in NIPT should be confirmed by invasive prenatal diagnosis before termination of pregnancy, and extensive pre- and post-test counselling is mandatory. In the future NIPT will replace first-trimester risk evaluation by nuchal translucency and biochemical markers, but should not replace first trimester ultrasound.

Affiliations

${ }^{1}$ Institut für Klinische Genetik Nordrhein, Essen, Germany

2 amedes Hamburg, Zentrum für Endokrinologie, Kinderwunsch und

Pränatale Medizin, Hamburg, Germany

${ }^{3}$ Genetic Department, amedes Institut f. Labormedizin und Klinische Genetik Institut f. Labormedizin und Klinische Genetik Rhein/ Ruhr MVZ GmbH,

Essen, Germany

${ }^{4}$ Genetic Department, amedes Institut f. Labormedizin und Klinische Genetik Rhein/ Ruhr MVZ GmbH, Essen, Germany

${ }^{5}$ MVZ FCH, amedes Hamburg, Zentrum für Pränatale Medizin, Hamburg,

Germany

${ }^{6}$ amedes Labor, Human Genetics, Hannover, Germany

${ }^{7}$ UFK Wien, Dep. for Prenatal Diagnostic and Therapy, Wien, Austria

${ }^{8} \mathrm{KH}$ Nordwest, Obstetrics \& Gynecology, Frankfurt/Main, Germany

References

1 Gil MM, Akolekar R, Quezada MS et al. Analysis of Cell-Free DNA in Maternal Blood in Screening for Aneuploidies: Meta-Analysis. Fetal Diagn Ther 2014; 35: 156-173

2 Palomaki GE, Deciu C, Kloza EM et al. DNA sequencing of maternal plasma reliably identifies trisomy 18 and trisomy 13 as well as Down syndrome: an international collaborative study. Genet Med 2012; 14 : 296-305 
3 Palomaki GE, Kloza EM, Lambert-Messerlian GM et al. DNA sequencing of maternal plasma to detect Down syndrome: an international clinical validation study. Genet Med 2011; 13: 913-920

4 Norton ME, Brar H, Weiss J et al. Non-Invasive Chromosomal Evaluation (NICE) Study: results of a multicenter prospective cohort study for detection of fetal trisomy 21 and trisomy 18. Am J Obstet Gynecol 2012; 207: 137.e1-137.e8

5 Sparks $A B$, Struble $C A$, Wang ET et al. Noninvasive prenatal detection and selective analysis of cell-free DNA obtained from maternal blood: evaluation for trisomy 21 and trisomy 18. Am J Obstet Gynecol 2012; 206: 319.e1-319.e9

6 Sparks AB, Wang ET, Struble CA et al. Selective analysis of cell-free DNA in maternal blood for evaluation of fetal trisomy. Prenat Diagn 2012; 32: 3-9

7 Zimmermann B, Hill M, Gemelos $G$ et al. Noninvasive prenatal aneuploidy testing of chromosomes $13,18,21, \mathrm{X}$, and $\mathrm{Y}$, using targeted sequencing of polymorphic loci. Prenat Diagn 2012; 32: 1233-1241

8 Samango-Sprouse C, Banjevic M, Ryan A et al. SNP-based non-invasive prenatal testing detects sex chromosome aneuploidies with high accuracy. Prenat Diagn 2013; 33: 643-649

9 Nicolaides KH, Syngelaki A, Gil MD et al. Prenatal Detection of Fetal Triploidy from Cell-Free DNA Testing in Maternal Blood. Fetal Diagn Ther 2014; 35: 212-217

10 Nicolaides KH, Syngelaki A, Gil M et al. Validation of targeted sequencing of single-nucleotide polymorphisms for non-invasive prenatal detection of aneuploidy of chromosomes 13, 18, 21, X, and Y. Prenat Diagn 2013; 33: 575-579

11 Samango-Sprouse C, Banjevic M, Ryan A et al. SNP-based non-invasive prenatal testing detects sex chromosome aneuploidies with high accuracy. Prenat Diagn 2013; 33: 643-649

12 Stellungnahme der Deutschen Gesellschaft für Humangenetik zur Analyse fetaler DNA aus dem mütterlichen Blut. www.gfhev.de/ leitlinien 2013

13 Eiben B, Thode C, Merz E. Nichtinvasive Pränataldiagnostik-Serumtestsyteme zur Erfassung von Chromosomenanomalien. Gynäkologie+Geburtshilfe 2013; 18: 2-4

14 Salomon LJ, Alfirevic Z, Audibert $F$ et al. ISUOG consensus statement on the impact of non-invasive prenatal testing (NIPT) on prenatal ultrasound practice. Ultrasound Obstet Gynecol 2014; 44: 122-123

15 Wegner R-D, Stumm M. Zytogenetische Methoden in der Pränataldiagnostik. medgen 2011; 23: 457-462
16 Hahnemann JM, Vejerslev LO. European collaborative research on mosaicism in CVS (EUCROMIC) - fetal and extrafetal cell lineages in 192 gestations with CVS mosaicism involving single autosomal trisomy. Am J Med Genet 1997; 70: 179-187

17 Grati FR, Malvestiti F, Ferreira JCPB et al. The role of feto-placental mosacism in false positive and false negative non-invasive prenatal screening (NIPS) results. Genet Med 2014, doi:10.1038/gim.2014.3 [Epub ahead of print]

18 Eiben B, Trawicki W, Haupt A et al. Discordant karyotypes in CVS and amniocenteses using cytogenetic and Fluorescence in Situ Hybridisation (FiSH) analyses. Prenat Diagn 1998; 18: 87-89

19 Kalousek DK, Barrett IJ, McGillivray BC. Placental mosaicism and intrauterine survival of trisomies 13 and 18. Am J Hum Genet 1989; 44: 338-343

20 Nicolaides KH, Syngelaki A, Gil M et al. Validation of targeted sequencing of single-nucleotide polymorphisms for non-invasive prenatal detection of aneuploidy of chromosomes 13, 18, 21, X, and Y. Prenat Diagn 2013; 33: 575-579

21 Mennuti MT, Athena MC, Morrissette JJD et al. Is it time to sound an alarm about false-positive cell-free DNA testing for fetal aneuploidy? Am J Obstet Gynecol 2013; 209: 415-419

22 Musci T. Letter to the editor. Prenatal Perspectives 2013; 1: 5

23 Pergament E, Cuckle H, Zimmermann B et al. Single-nucleotide polymorphism-based noninvasive prenatal screening in a high-risk and low-risk cohort. OBSTETRICS \& GYNECOLOGY 2014; 124: 210-218

24 Rava RP, Srinivasan A, Sehnert AJ et al. Circulating Fetal Cell-Free DNA Fractions Differ in Autosomal Aneuploidies and Monosomy X. Clinical Chemistry 2013

25 Dar P, Curnow KJ, Gross SJ et al. Clinical experience and follow-up with large scale single-nucleotide polymorphism-based non-invasive prenatal aneuploidy testing. American Journal of Obstetrics and Gynecology 2014, doi:10.1016/j.ajog.2014.08.006

26 Bianchi DW, Parker RL, Wentworth J et al. for the CARE Study Group. DNA Sequencing versus Standard Prenatal Aneuploidy Screening. N Engl J Med 2014; 370: 799-808

27 Kagan KO, Eiben B, Kozlowski P. Combined First Trimester Screening and Cell-Free Fetal DNA - "Next Generation Screening. Ultraschall Med 2014; 35: 229-236 